\title{
Analysis and Test of Conductive Shaft of Large Horizontal NC ECM Machine Tool
}

\author{
Lin Tang ( $\nabla$ tang_lin168@126.com ) \\ Xi'an Technological University \\ Yaze Zheng \\ Xi'an Technological University \\ Chengjin Shi \\ Xi'an Technological University \\ Lifeng Zhang \\ Xi'an Technological University \\ Zhao Wang \\ Xi'an Technological University
}

\section{Research Article}

Keywords: ECM machine tool, conductive shaft, thermal-electrical coupling mode, temperature field

Posted Date: November 2nd, 2021

DOI: https://doi.org/10.21203/rs.3.rs-1019548/v1

License: (c) (i) This work is licensed under a Creative Commons Attribution 4.0 International License. Read Full License 


\section{Abstract}

In order to solve the problems of serious heating and easy ablation of conductive shaft in electrochemical machining of special-shaped deep hole with large aspect ratio, the two schemes of single side copper bar and symmetrical copper bar of conductive shaft were studied by ANSYS software. And the conductive shaft scheme based on symmetrical copper bar scheme was determined. The thermoelectric coupling model of the conductive shaft was established to analyze the distribution law of temperature field and thermal deformation of conductive shaft under different working conditions. Through the machining test of special-shaped inner spiral deep hole parts with large aspect ratio, the results show that under the conditions of working current of $15000 \mathrm{~A}$, feed rate of $5 \mathrm{~mm} / \mathrm{min}$ and continuous machining for 14 hours, the forming accuracy of the workpiece is $\pm 0.15 \mathrm{~mm}$ and the surface roughness is better than $R a 0.8$ $\mu \mathrm{m}$. The performance of the conductive shaft is stable and meets the actual processing requirements. The heat dissipation performance of the conductive shaft can be optimized by providing air flow on the upper surface and side at the same time.

\section{Highlights}

- Conductive shaft is the core component of horizontal CNC electrochemical machining machine tool. The rationality of its structure and performance have a great impact on the machining quality of the machine tool, and even determine whether the electrochemical machining can be carried out smoothly.

- The two schemes of single side copper bar and symmetrical copper bar of conductive shaft were studied by ANSYS software. The maximum current of the symmetrical copper bar scheme is smaller, and the thermal deformation of the conductive shaft structure is significantly reduced.

- The heat dissipation performance of the conductive shaft can be optimized by providing air flow on the upper surface and side at the same time.

- The designed conductive shaft realized the stable and reliable processing of the special-shaped inner spiral deep hole parts with large length diameter ratio.

- The forming accuracy of the processed parts reached $\pm 0.15 \mathrm{~mm}$, and the surface roughness reached $R a 0.8 \mu \mathrm{m}$. Therefore, the conductive shaft has reasonable structure and meets the actual processing requirements.

\section{Introduction}

The special shaped inner spiral deep hole parts with large aspect ratio are widely used in weapons and equipment, petroleum drilling and production and other fields [1-3]. Due to high material hardness and complex inner spiral structure, traditional processing method cannot meet the actual needs. While electrochemical machining has the advantages of not limited by material mechanical properties, no cutting stress and high machining efficiency, it has become an irreplaceable processing method for such 
parts [4-10]. As the core component of horizontal NC ECM machine tool, the rationality of its structure and performance has a great impact on the reliable processing of the machine tool. Especially under the processing conditions of small gap, large current and high flow rate, the ECM machine tool can realize long-term stable, reliable, high-precision and high-efficiency processing.

Many scholars have carried out a lot of research work on the existing conductive shaft with serious heating, large structural deformation, and even ablation and shaft holding. In terms of processing technology, some scholars put forward the compound machining technology of EDM and ECM-lapping, which improves the surface roughness of the hole [11]. Some scholars optimized the processing parameters, realized the stability of the machine tool in actual processing and improved the efficiency of electrochemical machining [12-15]. Other scholars optimized the cathode movement path to improve the quality of electrochemical machining [16]. The special machining method combined with electrochemical machining and other machining methods had attracted the attention of relevant researchers and ensured the reliability of the machine tool [17]. In terms of machine tool design, literature [18] mainly studied the performance of horizontal ECM machine tool and optimized the performance. Document [19] conducted research on machining parts with complex inner surface using ECM technology. Through in-depth research on ECM, researchers combined ECM machine tools with the computer field, and used computeraided technology to complete the design of ECM cathode [20-24]. In view of the complex machining surface of parts, some scholars have realized the application of ECM rifling in practical production $[25,26]$. Document [27] constructed a knowledge base system to realize the intelligent selection of ECM parameters in combination with the characteristics of machine tools and machined workpieces. Some scholars had developed a desktop machine tool prototype called "The ion controlled desktop machine tool". The machine tool could automatically change the resistance of machining fluid and carry out complex machining and continuous complex machining on the same machine tool at the same time. [28]. Professor Fan [29] developed a horizontal two axis linkage NC ECM machine tool for the spiral machining of deep hole parts with large aspect ratio. The forming accuracy was $\pm 0.07 \mathrm{~mm}$ and a surface roughness of Ra0.8 $\mu \mathrm{m}$. Literature [30] designed a small magnetic drive ECM. The strength and deformation of ECM machine tool were analyzed. High precision machining of holes, surfaces and other shapes could be realized. Experiments show that the device meets the design requirements. ECM machine tools are developing towards large-scale, intelligent and high-precision [31-34].

Aiming at the problem of serious heating and even ablation of the existing conductive shaft, this paper proposes an overall design structure of the conductive shaft based on the symmetrical copper bar power transmission scheme, which is suitable for large horizontal NC ECM machine tools. By establishing the thermoelectric coupling model of the conductive shaft, the temperature field of the conductive shaft was simulated and analyzed, and the distribution law of the temperature field of the conductive shaft under different working conditions was studied, Finally, the designed conductive shaft was applied to the large horizontal NC ECM machine tool to verify the reliability of the structural design of the conductive shaft.

\section{Structural Design Of Conductive Shaft}


The conductive shaft structure of large horizontal NC ECM machine tool is mainly composed of power introduction part, support part, rotary sealing part and other accessories. All parts cooperate with each other to complete the functions of conductive shaft, such as conduction, rotation, sealing, etc.

\subsection{Overall structure of conductive shaft}

The threaded hole was preset on the base plate, and the support assembly was fixed on the floor through the connection between the bolt and the threaded hole. During installation, the base plate passed through the conductive shaft body and adjusted the position to ensure that the support assembly can support the conductive shaft. Fix the support assembly on the floor through bolts to complete the overall installation of the conductive shaft. Finally, the elastic force of the carbon brush holder was debugged so that the shaft could be rotated while the carbon brush was pressing the axis of the conductive shaft. The overall scheme of the conductive shaft is shown in Fig.1.

\subsection{The power transmission structure}

The circuit designed in this paper is to control the rotation of one end and the static stable and reliable power supply at the other end. The carbon brush conduction is to press the carbon brush on the circumferential surface of the conductive shaft by using the elastic force. And the carbon brush is fixed on the base plate to realize the power supply between the fixed part and the relative rotating part. The schematic diagram of the carbon brush power supply scheme is shown in Fig. 2.

Changing the number of carbon brushes or base plates can provide different sizes of current with high flexibility. When installing the carbon brush holder, the angle of the carbon brush holder can be adjusted to make it at a certain angle with the normal direction of the conductive shaft body, so that the force on the carbon brush is more uniform in the process of rotation and the whole rotation process is more stable. The specific way of using carbon brush to lead electricity is: draw the current from the negative

pole of the power supply, enter the power leading device through the cable, connect the carbon brush and conductive shaft with the current by relying on the base plate. Finally, the current on the conductive shaft is guided to the cathode by the pull rod. Two placement schemes of single side copper bar and symmetrical copper bar were proposed. The carbon brush holder was simplified into a carbon brush. And the simplified three-dimensional model is shown in Fig.3.

The maximum working current of large horizontal NC ECM machine tool can reach $20000 \mathrm{~A}$. With the accumulation of time, the thermal effect of current will produce a lot of heat in the current flowing area. The increase of temperature is easy to cause thermal deformation of the conductive shaft, which will reduce the positioning accuracy of the conductive shaft. The conductive shaft will not work in severe cases. Import the three-dimensional model files of the above two schemes into the workbench as the electric field simulation model. Set the surface contact coefficient to simulate the conductive efficiency between the carbon brush holder and the substrate and between the carbon brush holder and the 
conductive shaft in the actual conductive process. The location where the conductive shaft often fails is in the contact area between the carbon brush and the conductive shaft. In order to accurately analyze the current at these locations during operation, the grids at these locations were encrypted, as shown in Fig.4.

When setting the boundary conditions, take the side of the lead copper bar as the position where the current is applied. The flow direction of the current is from the copper bar to the substrate, and the current flows into the shaft body of the conductive shaft by means of the carbon brush. It is necessary to set the front face of the conductive shaft to the 0 voltage level, so as to ensure the flow direction of the current. The electric field distribution of the two different lead schemes is shown in Fig.5. As shown in Fig.5 (a), the electric field of the unilateral power transmission scheme is the area with the highest current density. As can be seen from Fig.5 (b), the area of bilateral power transmission is also the area with the highest current density, which is different from the unilateral power transmission, The symmetrical copper bar scheme can make the electric field evenly distributed on both sides of the substrate and greatly reduce the maximum current density.

The maximum current of the symmetrical copper bar scheme is smaller, and the thermal deformation of the conductive shaft structure is significantly reduced. The temperature field distribution generated by the current can be homogenized to make the thermal expansion deformation uniform and reduce the thermal expansion deformation as a whole. Therefore, the symmetrical copper bar scheme was selected for research.

\subsection{The supporting structure}

In the conductive shaft device, the support part is mainly used to support the conductive shaft and ensure that the conductive shaft can complete the predetermined rotation function. The support assembly is used to support and rotate the conductive shaft body. The support assembly was composed of main shaft support, bearing, upper support cross bar and support pull rods on both sides, and was fixed with nut main shaft support. The structure can realize the accurate positioning of the conductive shaft body, adjust the position of the conductive shaft body by relying on the bolts on the support, and facilitate maintenance and disassembly while completing the support and rotation function of the conductive shaft.

\subsection{The rotary seal structure}

The sealing structure of the conductive shaft adopted the combination of mechanical seal and packing seal to ensure the reliable sealing of the conductive shaft in the working process. The sealing structure is shown in Fig.6. The primary seal of the sealing device was mechanical seal, which adopted the combination of moving ring and static ring. The moving ring was pressed on the bushing according to the elastic force and rotates with the conductive shaft. The static ring was in close contact with the outer cavity shell of the rotary sealing structure by means of tension, and remained relatively stationary. The contact surface of the two will have a layer of dense liquid film, which reduced the friction between the dynamic ring and the static ring, realized the sealing and completes the preset rotation function at the 
same time. The secondary packing seal of the rotary sealing device was the packing seal, and the filler was organic synthetic fiber and carbon fiber, which was conducive to the stable operation of the rotary sealing device.

\section{The Temperature Field Simulation Of Conductive Shaft}

In order to reduce the amount of calculation and improve the calculation accuracy, it is necessary to simplify or delete the structure independent of the temperature field when analyzing the temperature field of the conductive shaft structure. The established physical three-dimensional model is shown in Fig.7. Only the components with current passing through during the processing were considered. The model mainly includes the conductive shaft body, substrate, carbon brush, copper bar, etc.

ANSYS software is used to simulate and analyze the temperature field of the conductive shaft. The threedimensional model of the conductive shaft was imported into the workbench to establish the thermoelectric coupling model of the conductive shaft. The conductive shaft and carbon brush materials were set as red copper and graphite respectively. The geometric model was meshed. In order to obtain accurate calculation results, these positions were divided in detail. The conventional free tetrahedral mesh was selected for the rest of the region. And the convective heat transfer coefficient and the thermal radiation coefficient were added for solution, boundary conditions and loads.

\subsection{The transient temperature field and thermal deformation of conductive shaft}

The transient temperature field of the conductive shaft was analyzed. The duration of electrochemical machining a complete workpiece was 8 hours. The simulation time was set as $28800 \mathrm{~s}$, which was

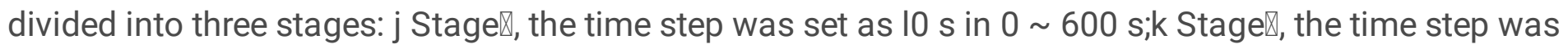

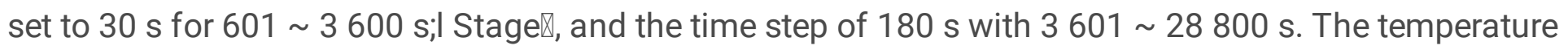
field simulation and thermal deformation of the conductive shaft were carried out under the conditions of working current $12000 \mathrm{~A}$ and the ambient temperature of $23^{\circ} \mathrm{C}$. The current density distribution is shown in Fig.8, the section transient temperature field is shown in Fig. 9, and the thermal deformation of the temperature field is shown in Fig.10 when the conductive shaft reaches a stable state in the processing process. As can be seen from figure 8 , the positions with the maximum current density are at the front end of the conductive shaft and the area where the conductive shaft contacts the carbon brush. The area at the connection between the carbon brush and the conductive shaft is small. The current passing through all the carbon brushes is collected at the front end of the conductive shaft, resulting in relatively high current density at these positions.

As can be seen from Fig.9, the highest temperature is in the area where the carbon brush contacts the conductive shaft on the substrate and the position where the front end of the conductive shaft extends out of the substrate because the current is collected at these positions. The temperature of the conductive shaft increases with time. After 2400 seconds, the distribution of the overall temperature field of the conductive shaft does not change and reaches a stable state. 
The thermal deformation when the temperature field of the conductive shaft reaches a stable state is shown in Fig.10. The maximum thermal deformation area is the upper end of the most front substrate. The overall deformation of the conductive shaft is not only related to its own temperature, but also affected by the deformation of other parts. The maximum thermal deformation is the result of the comprehensive influence of its own temperature and the deformation of other parts.

\subsection{The effect of processing current on temperature field of conductive shaft}

The temperature field of the conductive shaft structure was analyzed when the initial ambient temperature was $23^{\circ} \mathrm{C}$ and the processing current was $12000 \mathrm{~A}, 15000 \mathrm{~A}$ and $20000 \mathrm{~A}$ respectively. The temperature field after the conductive shaft reaches a stable state is shown in Fig.11. As can be seen from Fig.11, the temperature of the overall structure shows an upward trend with the increase of the processing current of the conductive shaft. Under different processing current conditions, the temperature at the front end of the conductive shaft is much higher than that at the rear end of the conductive shaft.

\section{3 The effect of ambient temperature on temperature field of conductive shaft}

The processing current was set to $12000 \mathrm{~A}$ and the ambient temperature was $5{ }^{\circ} \mathrm{C}, 15^{\circ} \mathrm{C}, 25^{\circ} \mathrm{C}$ and 35 ${ }^{\circ} \mathrm{C}$. The temperature field of the conductive shaft was analyzed. The variation law of the temperature field of the conductive shaft with the ambient temperature is shown in Fig.12. With the increase of the ambient temperature, the temperature of the overall structure of the conductive shaft shows an upward trend. At different ambient temperatures, the highest temperature appears in the front end of the conductive shaft.

\section{Optimize The Heat Dissipation Performance Of Conductive Shaft}

The temperature field of the conductive shaft is improved by improving the flow field in the conductive axle box. The cuboid $A B C D-E F G H$ represents the conductive shaft box. The simulation model established by fluent fluid analysis software is shown in Fig. 13. The steady-state temperature of the conductive shaft was taken as the initial temperature of the conductive shaft, and the improvement effect of different heat dissipation methods on the conductive shaft temperature field was analyzed. There are three heat dissipation schemes: $\phi$ Scheme I, an air source is set at the plane $A B C D$ of the box; $\mathrm{K}$ Scheme II, set the air source at the plane $C D E F$ of the box; $\lambda$ Scheme III, the air source was set at the plane $A B C D$ and plane $C D E F$ of the box at the same time.

When the processing current is $20000 \mathrm{~A}$ and the ambient temperature is $23^{\circ} \mathrm{C}$, the flow field distribution of different schemes is shown in Fig. 14. Fig. 14(a) shows the flow field distribution around the conductive shaft in scheme I. After the cold air flows through the conductive shaft, the original uniform flow field changes. On the side away from the plane $A B C D$, a large number of areas cannot contact the cold air flow, and the temperature in this area is significantly higher than that in other areas. The flow field distribution around the conductive shaft in scheme II is shown in Fig. 14(b). There are still a large number of areas at the bottom of the conductive shaft that cannot contact the cold air flow. The flow field 
distribution around the conductive shaft in scheme III is shown in Fig. 14(c). Compared with scheme I and scheme II, most structures of the conductive shaft can be fully contacted with the cold air flow. The temperature difference increases the convective heat transfer coefficient on the surface of the conductive shaft and significantly reduces the temperature in the axle box. It can be seen that scheme III can significantly improve and optimize the heat dissipation performance of the conductive shaft.

The air flow at the inlet was set at different temperatures to study the improvement of the thermal characteristics of the conductive shaft after using the refrigeration equipment. The average surface temperature of the conductive shaft varies with the temperature at the inlet. As shown in Fig. 15, the average temperature of the axle box has a linear positive correlation with the inlet temperature. The lower the temperature at the inlet, the lower the average temperature of the conductive shaft. When the air source is set to make the inlet temperature at $15^{\circ} \mathrm{C}$, the maximum average surface temperature of the conductive shaft is about $70{ }^{\circ} \mathrm{C}$.

Add refrigeration equipment on the original conductive axle box, install the conductive shaft on the machine bed. Set an insulating block between the bottom plate of the conductive shaft and the machine bed. And insulate the conductive shaft device from the machine bed to ensure the overall insulation of the machine bed. The physical object after the installation and commissioning of the conductive shaft is shown in Fig. 16.

\section{The Process Test}

For the large horizontal NC ECM machine tool, the working current is up to $20000 \mathrm{~A}$, the machine body is about 16 meters long, and the machining gap between cathode and workpiece is only $0.5 \sim 1 \mathrm{~mm}$. The verification test is carried out on a large horizontal NC ECM system. Through the process test, the rationality and stability of the conductive shaft structure are verified. The processing parameters used in the test are shown in Tab.1.

Tab. 1 The test processing parameters

\begin{tabular}{|c|c|c|c|c|}
\hline Parameters & $\begin{array}{l}\text { Processing } \\
\text { Voltage (V) }\end{array}$ & $\begin{array}{l}\text { Feed Rate } \\
\bigotimes \mathrm{mm} / \mathrm{min} \rrbracket\end{array}$ & $\begin{array}{l}\text { Electrolytic Pressure } \\
₫ \mathrm{MPa} \rrbracket\end{array}$ & $\begin{array}{l}\text { Electrolyte } \\
\text { Temperature }\left({ }^{\circ} \mathrm{C}\right)\end{array}$ \\
\hline Value & $10 \bigotimes 15$ & 5 & 1.5 & 30 \\
\hline
\end{tabular}

The finished workpiece is shown in Fig.17 (a), and the sliced workpiece is shown in Fig.17 (b).

Number the sliced workpieces according to the processing sequence. Measure and record the size of the processed workpieces. Some data of the sliced size error and surface roughness measured after processing are shown in Tab.2. The data analysis shows that the forming accuracy of the workpieces reaches $\pm 0.15 \mathrm{~mm}$ and the surface roughness reaches $\mathrm{Ra} 0.8 \mu \mathrm{m}$. It can well meet the actual processing requirements. 
Tab.2 The workpiece number and measured value

\begin{tabular}{|lll|}
\hline Sample Number & Dimensional Error $(\mathrm{mm})$ & Surface Roughness $(\mu \mathrm{m})$ \\
\hline 1 & 0.14 & 0.75 \\
\hline 2 & 0.10 & 0.77 \\
\hline 3 & 0.06 & 0.78 \\
\hline 4 & 0.12 & 0.76 \\
\hline 5 & 0.05 & 0.74 \\
\hline 6 & 0.13 & 0.79 \\
\hline
\end{tabular}

\section{Conclusion}

In this paper, the structure, temperature field and heat dissipation performance of the conductive shaft of large horizontal NC ECM machine tool are analyzed. The main conclusions are as follows:

1) By establishing the finite element model of the conductive shaft of large horizontal NC ECM machine tool, the temperature field of the conductive shaft was analyzed, and a new conductive shaft structure based on symmetrical copper bar was proposed.

2) The results show that the maximum thermal deformation is at the substrate, and the current has a significant effect on the temperature rise of the conductive shaft. The heat dissipation performance of the conductive shaft can be significantly improved by providing air flow on the upper surface and side at the same time.

3) Under the conditions of current $15000 \mathrm{~A}$, feed speed $5 \mathrm{~mm} / \mathrm{min}$ and continuous processing for 14 hours, the stable and reliable processing of special-shaped internal spiral deep hole parts with large aspect ratio could be realized, the forming accuracy of processed workpiece could reach $\pm 0.15 \mathrm{~mm}$ and the surface roughness and reach $R a 0.8 \mu \mathrm{m}$.

\section{Declarations}

\section{Authors' contribution}

Lin Tang was the main contributor and corresponding author of the manuscript. Professor Lin Tang designed the research process, and led Yaze Zheng and Zhao Wang to finish the structure design of conductive shaft and the simulation of temperature field. Lifeng Zhang and Chengjin Shi completed the structural performance verification experiment of conductive shaft and guided the manuscript writing.

\section{Funding information}


This work was financially supported by Shaanxi Province Key Research and Development projects (Grant No. 2020GY-153), Scientific research program for Youth Innovation Team Construction of Shaanxi Provincial Department of Education (No: 21JP054), and Shaanxi University Youth Innovation Team Project (Grant No: 20201020).

\section{Availability of data and materials}

All data generated or analyzed during this study are included in this published article.

\section{Ethics approval}

Not applicable.

\section{Consent to participate}

Not applicable.

\section{Consent for publication}

Not applicable.

\section{Conflict of interest}

The authors declare no competing interests.

\section{References}

1. Wang GQ, Li HS, Zhang C, Zhu D (2019) Improvement of machining consistency during throughmask electrochemical large-area machining. Chinese Journal of Aeronautics 32(04):1051-1058.

2. El-Hofy H (2019) Vibration-assisted electrochemical machining: a review. The International Journal of Advanced Manufacturing Technology 105(1-4):579-593.

3. Liu J, Wang H, Zhu D (2018) Electrochemical machining of $Y$-TiAl intermetallic blades by using the stainless steel anti-copied tool electrodes. Procedia CIRP 68:757-761.

4. Burger M, Koll L, Werner E.A, Platz A (2012) Electrochemical machining characteristics and resulting surface quality of the nickel-base single-crystalline material LEK94. Journal of Manufacturing Processes 14(1):62-70.

5. Holstein N, Krauss W, Konys J (2011) Development of novel tungsten processing technologies for electrochemical machining (ECM) of plasma facing components. Fusion Engineering and Design 86(9-11):1611-1615.

6. Dhobe S.D, Doloi B, Bhattacharyya B (2011) Surface characteristics of ECMed titanium work samples for biomedical applications. The International Journal of Advanced Manufacturing Technology 55(1-4):177-188. 
7. Tang L, Li B, Yang S, Duan QL, Kang BY (2014) The effect of electrolyte current density on the electrochemical machining S-03 material. The International Journal of Advanced Manufacturing Technology 71(9-12):1825-1833.

8. Tang L, Guo YF (2013) Experimental study of special purpose stainless steel on electrochemical machining of electrolyte composition. Materials and Manufacturing Processes 28 (4) : 457-462.

9. Zhu ZW, Wang DY, Bao J, Wang NF, Zhu D (2015) Cathode design and experimental study on the rotate-print electrochemical machining of revolving parts. The International Journal of Advanced Manufacturing Technology 80(9-12):1957-1963.

10. Jia JL, Liu JH, Wang X (2015) Experimental investigation on the inner cavity of gun barrel chamber in electrochemical machining. International Journal of Control and Automation 8(4):169-180.

11. Kurita T, Hattori M (2006) A study of EDM and ECM/ECM-lapping complex machining technology. International Journal of Machine Tools and Manufacture 46:1804-1810.

12. Asokan P, Kumar R.R, JeyapaulL R, Santhi M (2008) Development of multi-objective optimization models for electrochemical machining process. The International Journal of Advanced Manufacturing Technology 39(1-2):55-63.

13. Mukherjee R, Chakraborty S (2013) Selection of the optimal electrochemical machining process parameters using biogeography-based optimization algorithm. The International Journal of Advanced Manufacturing Technology 64(5-8):781-791.

14. Damme S.V, Nelissen G, Bossche B.V.D, Deconinck J (2006) Numerical model for predicting the efficiency behavior during pulsed electrochemical machining of steel in $\mathrm{NaNO}_{3}$. Journal of applied electrochemistry 36(1):1-10.

15. Tang L, Yang S (2013) Experimental investigation on the electrochemical machining of 00Cr12Ni9Mo4Cu2 material and multi-objective parameters optimization. The International Journal of Advanced Manufacturing Technology 67(9-12):2909-2916.

16. Qu NS, Xu ZY (2013) Improving machining accuracy of electrochemical machining blade by optimization of cathode feeding directions. The International Journal of Advanced Manufacturing Technology 68(5-8):1565-1572.

17. Zhang ZY, Feng QY, Cai MX, Huang L, Jiang YJ (2015) Research on stress-etching complex microstructure of aluminum alloy in laser electrochemical machining. The International Journal of Advanced Manufacturing Technology 81(9-12):2157-2165.

18. Liu GX, Zhang YJ, Luo HP, Zhou C, Wang YN, Zhang CY (2016) Large lead ball nut raceway ECM machine tool. Electrical machining and die (1): 59-61. \in Chinese》

19. Wang MH, Peng W, Yao CY, Zhang QF (2010) Electrochemical machining of the spiral internal turbulator. The International Journal of Advanced Manufacturing Technology 49(8-12):969-973.

20. Mahdavinejad R, Mehraban M, Mahdavinejad D (2006) The behaviour of REFEL SiC under electrodischarge machining. Proceedings of the Institution of Mechanical Engineers, Part B: Journal of Engineering Manufacture 220(10):1635-1646. 
21. Xu ZY, Liu J, Xu Q, Gong T, Zhu D, Qu NS (2015) The tool design and experiments on electrochemical machining of a blisk using multiple tube electrodes. The International Journal of Advanced Manufacturing Technology 79(1-4):531-539.

22. Kozak J, Chuchro M, Ruszaj A, Karbowski K (2000) The computer aided simulation of electrochemical process with universal spherical electrodes when machining sculptured surfaces. Journal of Materials Processing Technology 107(1-3):283-287.

23. Purcar M, Dorochenko A, Bortels L, Deconinck J, Van den B.B (2007) Advanced CAD integrated approach for 3D electrochemical machining simulations. Journal of Materials Processing Technology 203(1-3):58-71.

24. Pattavanitch J, Hinduja S, Atkinson J (2010) Modelling of the electrochemical machining process by the boundary element method. CIRP Annals - Manufacturing Technology 59(1):243-246.

25. Tang L, Gan WM (2014) Utilization of flow field simulations for cathode design in electrochemical machining of aerospace engine blisk channels. The International Journal of Advanced Manufacturing Technology 72(9-12):1759-1766.

26. Mahdavinejad R, Hatami M (2008) On the application of electrochemical machining for inner surface polishing of gun barrel chamber. Journal of Materials Processing Technology 202(1-3):307-315.

27. Amalnik M, McGeough J (1996) Intelligent concurrent manufacturability evaluation of design for electrochemical machining. Journal of Materials Processing Technology 61(1):130-139.

28. Tsuneo K, Chiaki E, Yasuhiro M, Hiroshi M, Kazuhiro T, Fumitaka T, Hiromichi I, Keigo O, Kouji K (2008) Mechanical/electrochemical complex machining method for efficient, accurate, and environmentally benign process. International Journal of Machine Tools \& Manufacture 48 :15991604.

29. Tang L, Fan ZJ, Zhao GG, Yang F, Yang S (2016) High aspect ratio deep spiral tube electrochemical machining technology. Procedia CIRP 42:407-411.

30. Zhang CF, Wang FG, Xu SY (2011) A Small Magnetic Driving ECM Machine. Advanced Materials Research 411(000): 72-76.

31. Jeon D H, Kim B H, Chu C N (1966) Micro Machining by EDM and ECM. Journal of the Korean Society of Precision Engineering (1225-9071) 23(10) 52-59.

32. Alexandre S, Atanas I (2015) Design of an electrochemical micromachining machine. The International Journal of Advanced Manufacturing Technology 78(5-8): 737-752》

33. Zhong H, Tong H, Wang ZQ, Li Y, Pu YB (2020) Scanning Micro-Electrochemical Machining Process for V-Shaped Grooves. Journal of Micro and Nano-Manufacturing 8(1).

34. Sindt O, Akbari $\mathrm{H}$, Ramier J (2021) Fabrication of high aspect-ratio tungsten microtools through controlled electrochemical etching. Materials and Manufacturing Processes 36(11):1236-1247.

\section{Figures}




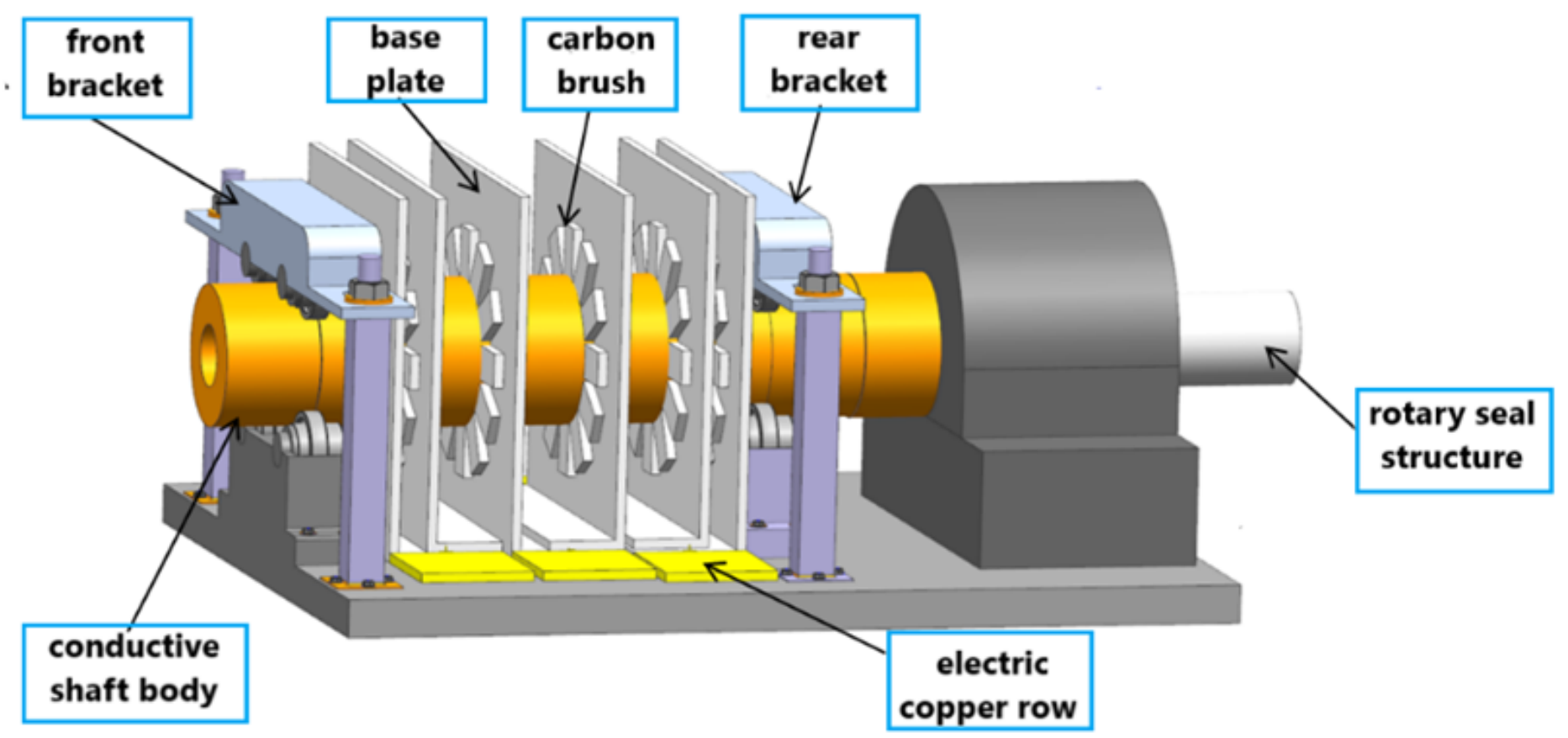

Figure 1

The overall structure model of conductive shaft

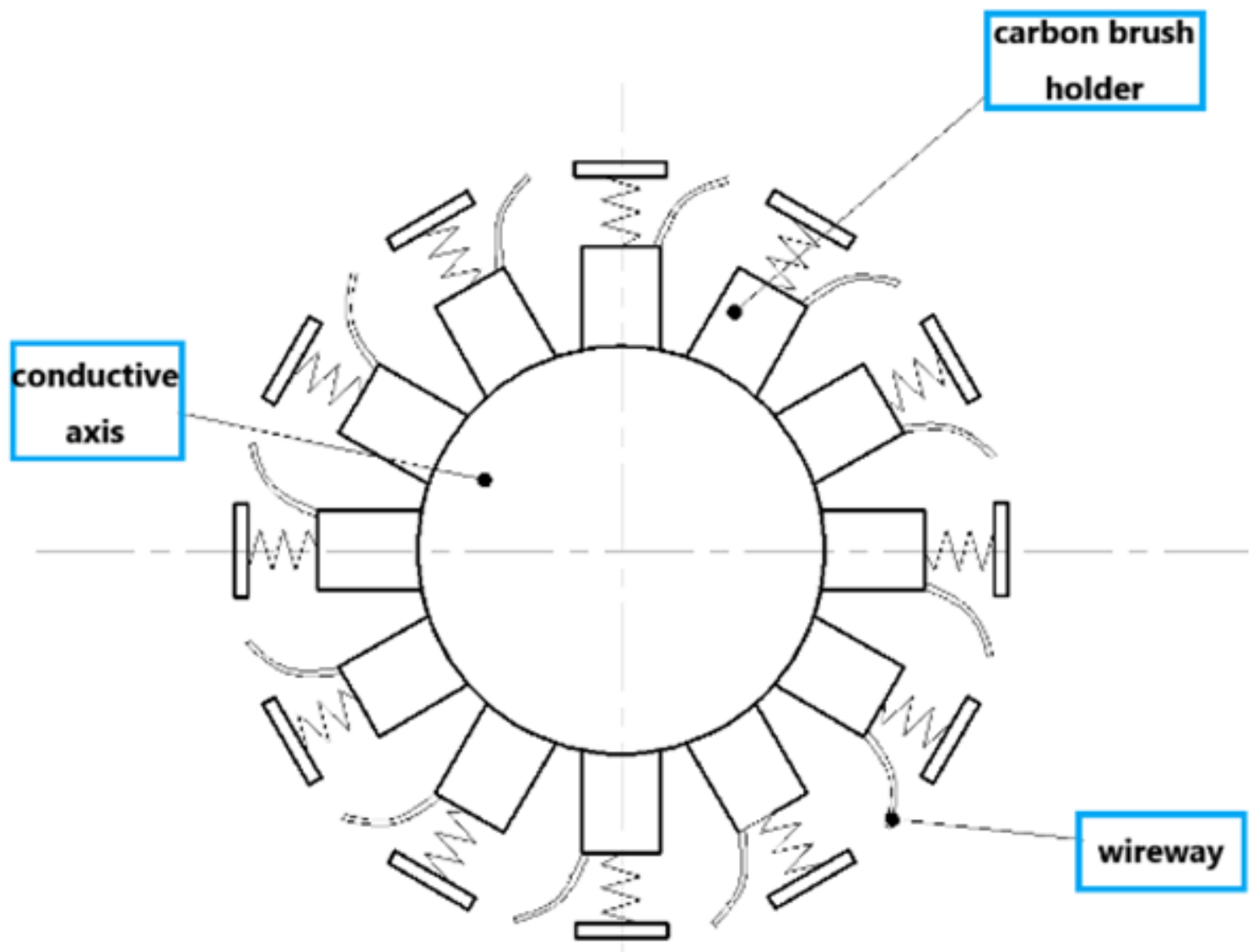

Figure 2 


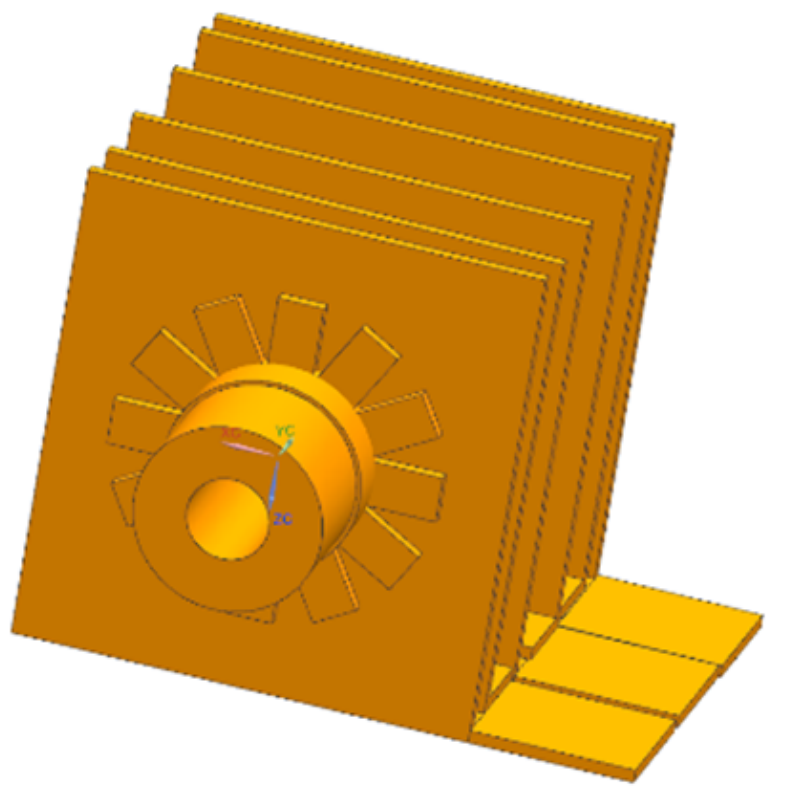

(a) The single side copper bar

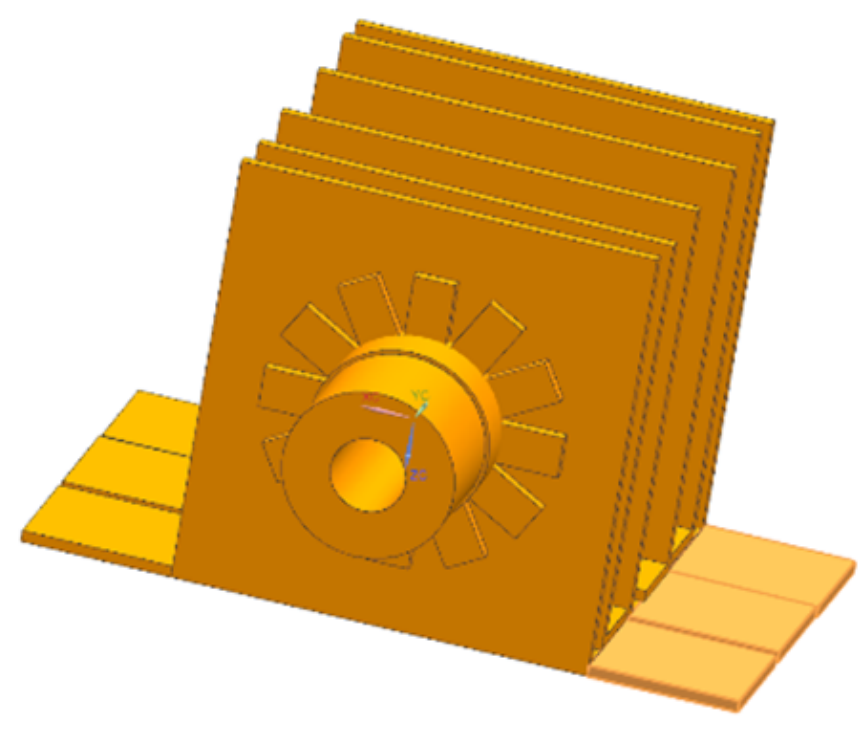

(b) The symmetrical copper bar

\section{Figure 3}

The placement scheme of conductive shaft lead copper bar

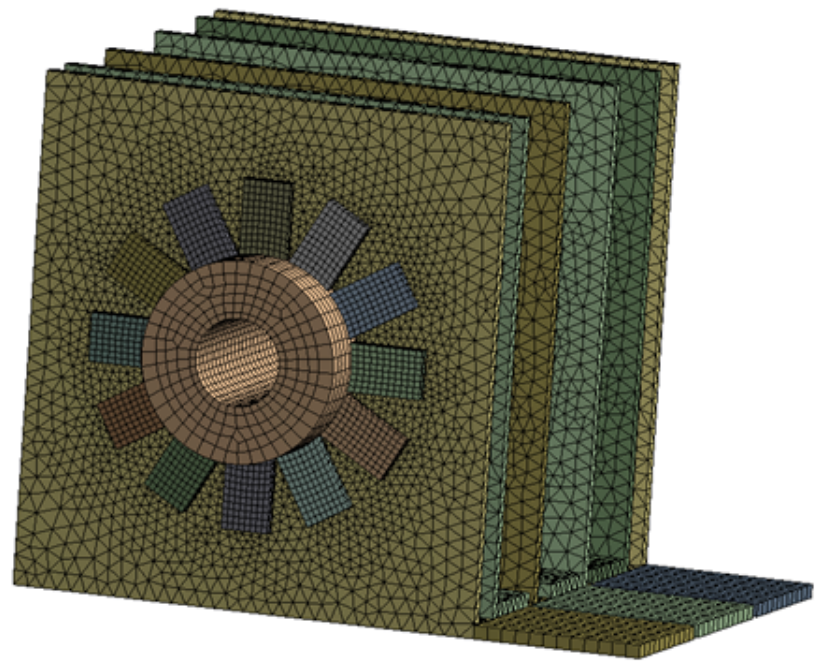

(a) The single side copper bar

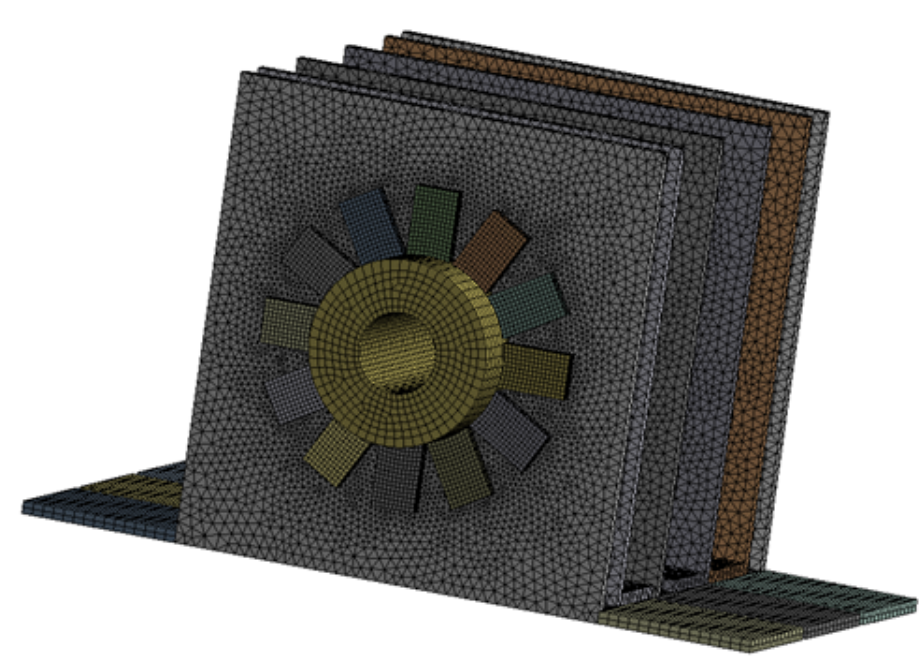

(b) The symmetrical copper bar

Figure 4

The grid division of power transmission scheme 


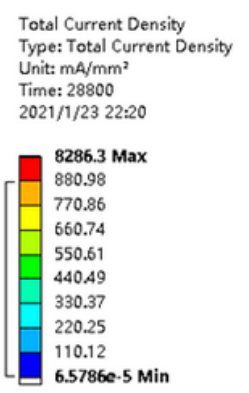

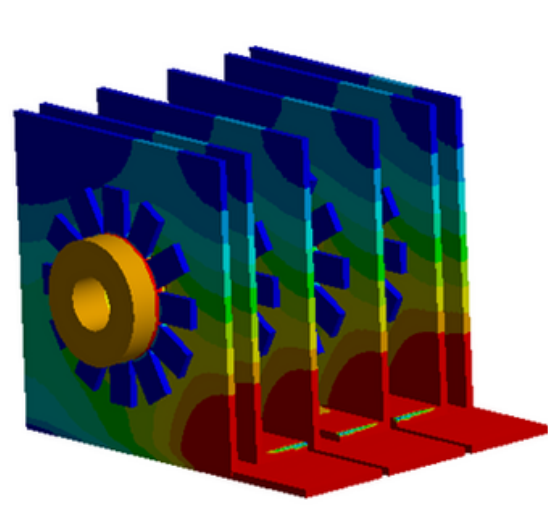

(a) The single side copper bar
Total Current Density

Type: Total Current Density

Time: 28800

Time: 280002012

3531.1 Max

880.98

770.86
660.74

550.61

440.49

330.37

220.25
110.12

$0.00013902 \mathrm{Min}$

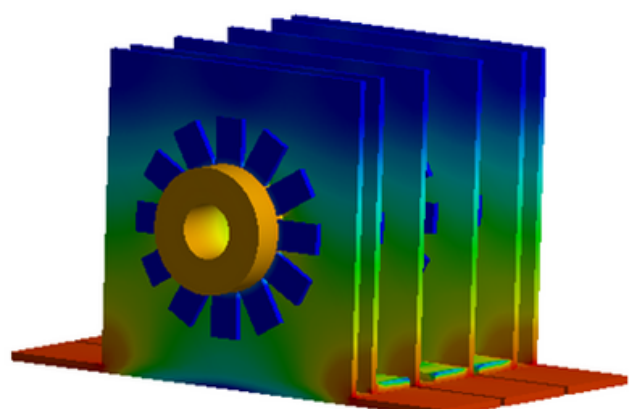

(b) The symmetrical copper bar

Figure 5

The current density distribution of different power introduction modes

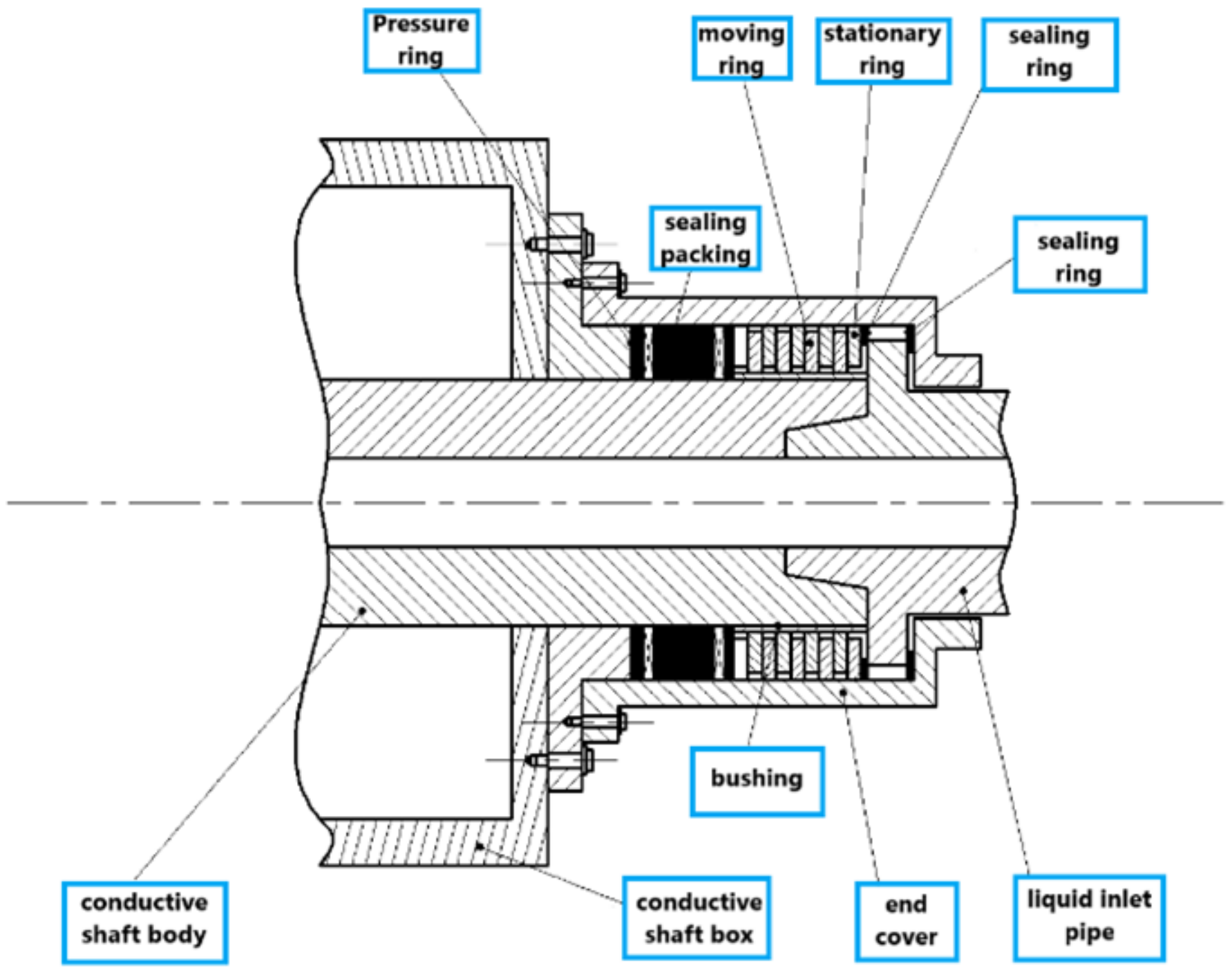


Figure 6

The seal structure diagram

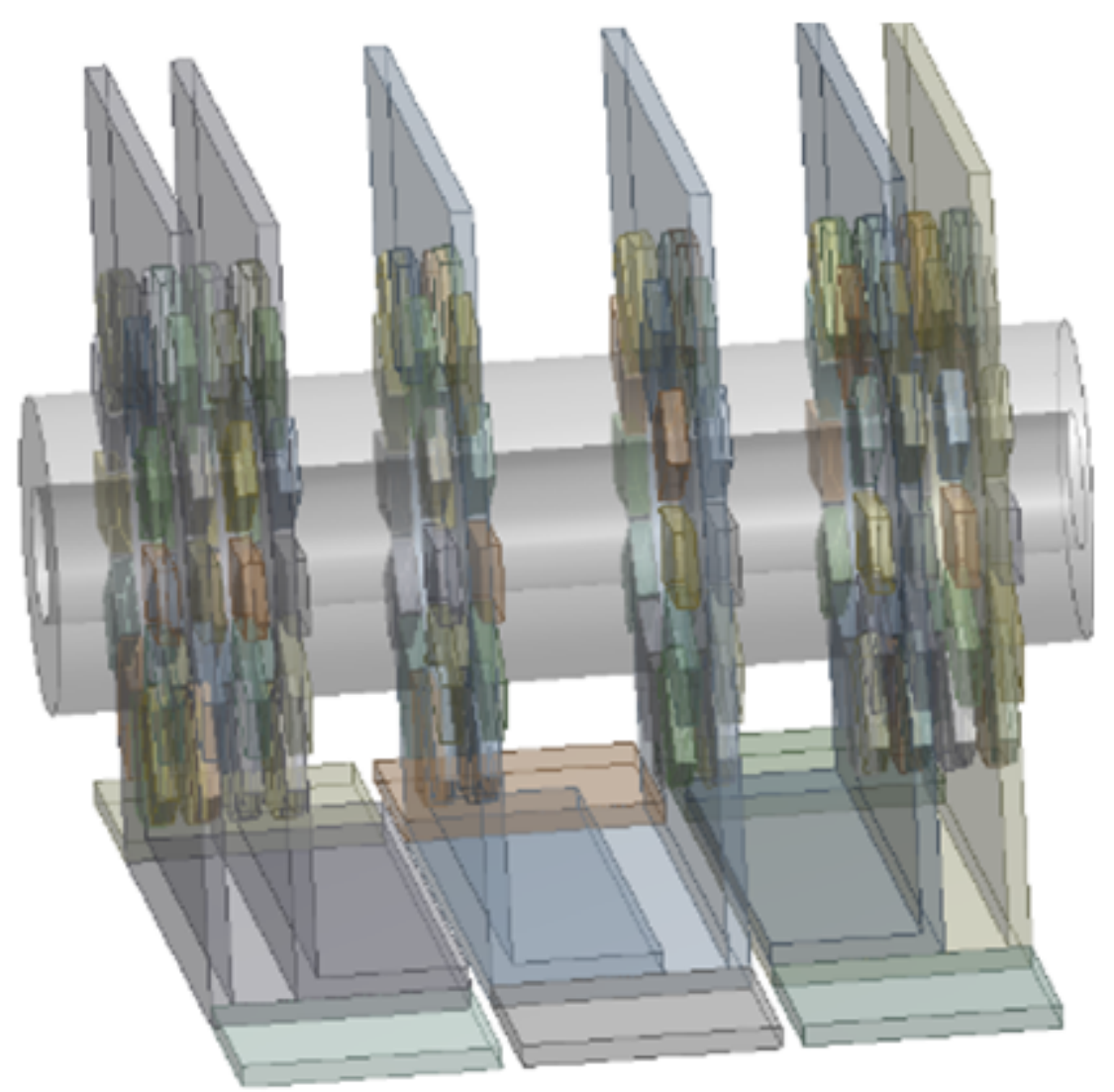

Figure 7

The simulation model of temperature field of conductive shaft

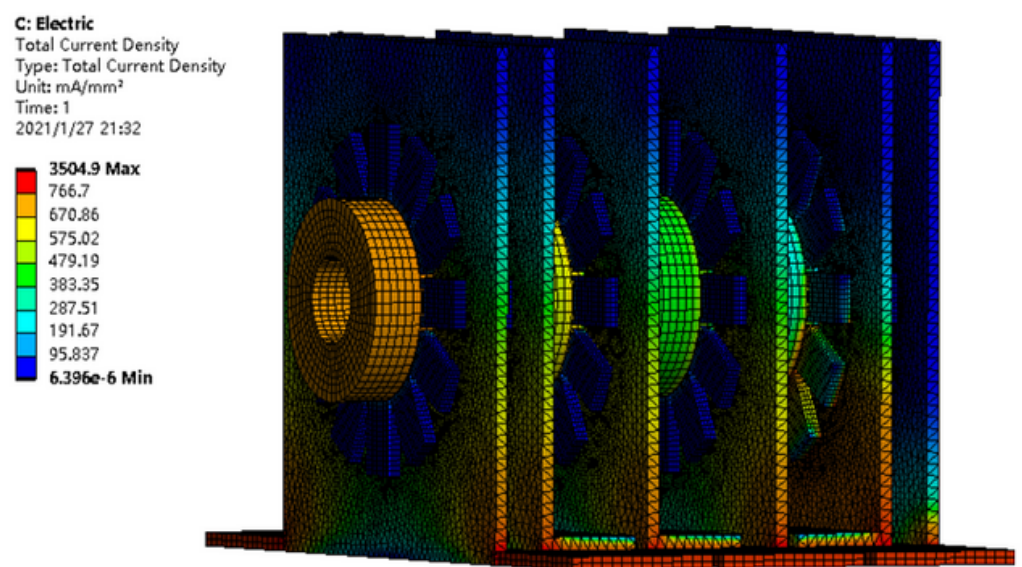

(a) Overall current density distribution

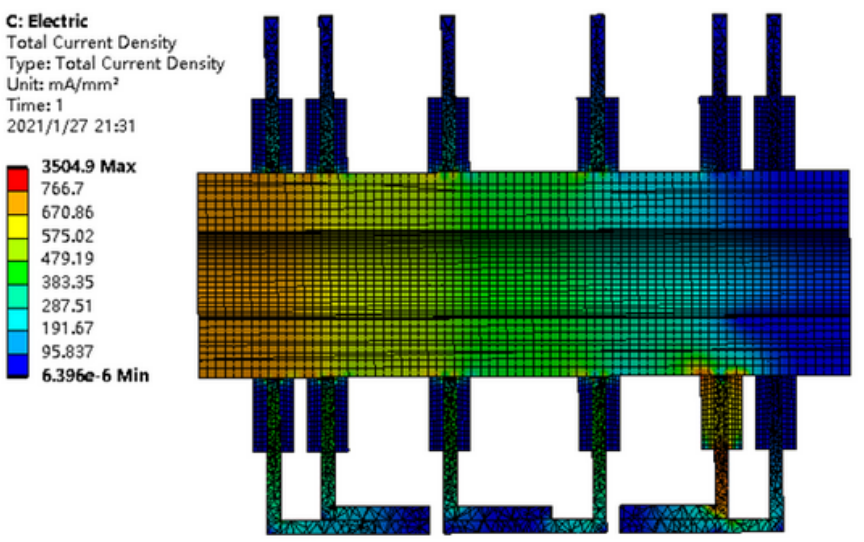

(b) Current density side section

Figure 8 
The current density diagram of conductive shaft

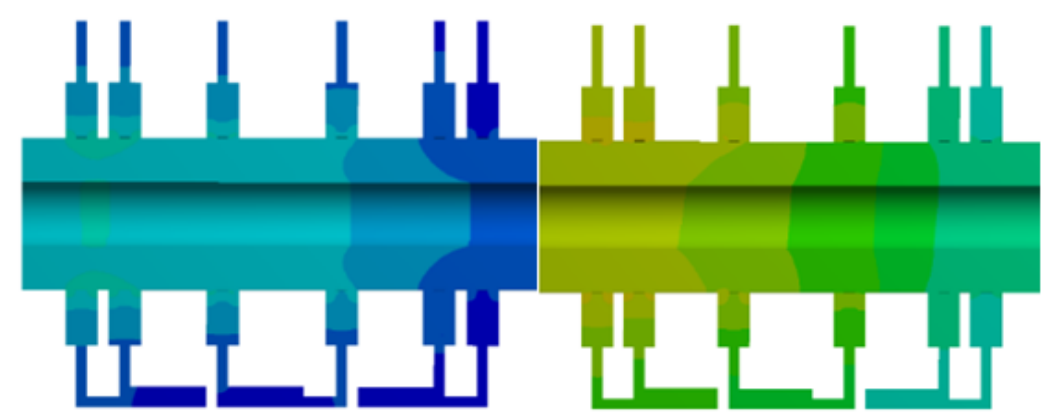
(a) $300 \mathrm{~s}$
(b) $600 \mathrm{~s}$

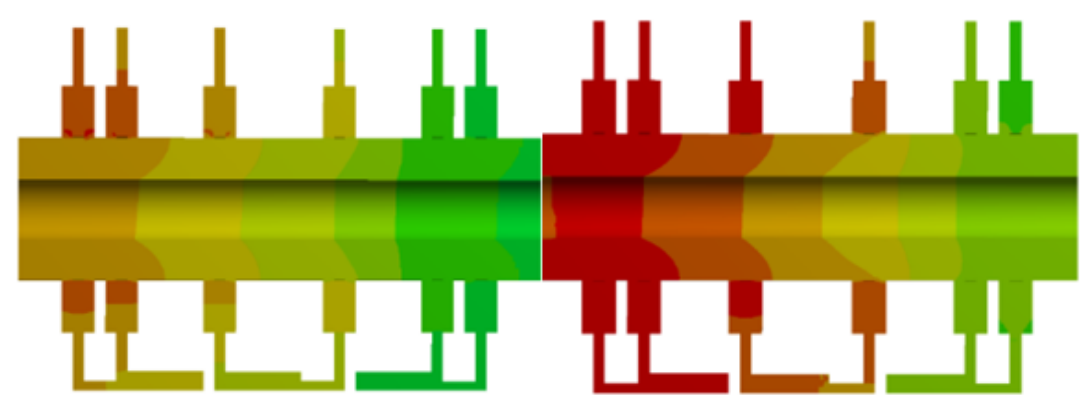

(c) $1200 \mathrm{~s}$

(d) $2400 \mathrm{~s}$

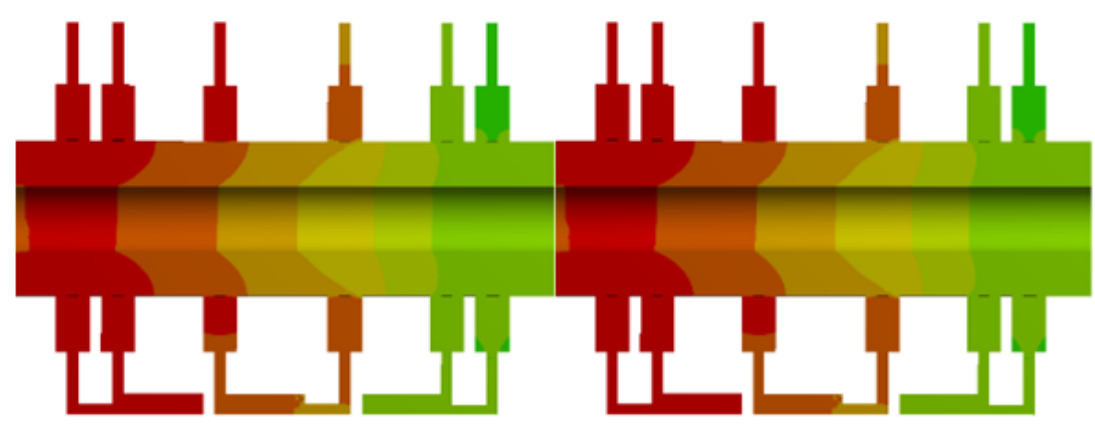

(e) $3600 \mathrm{~s}$

(f) $7200 \mathrm{~s}$

Temperature

Type:Temperature

Unit: ${ }^{\circ} \mathrm{C}$

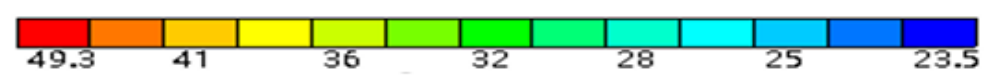

Figure 9

The transient temperature field of conductive shaft section 


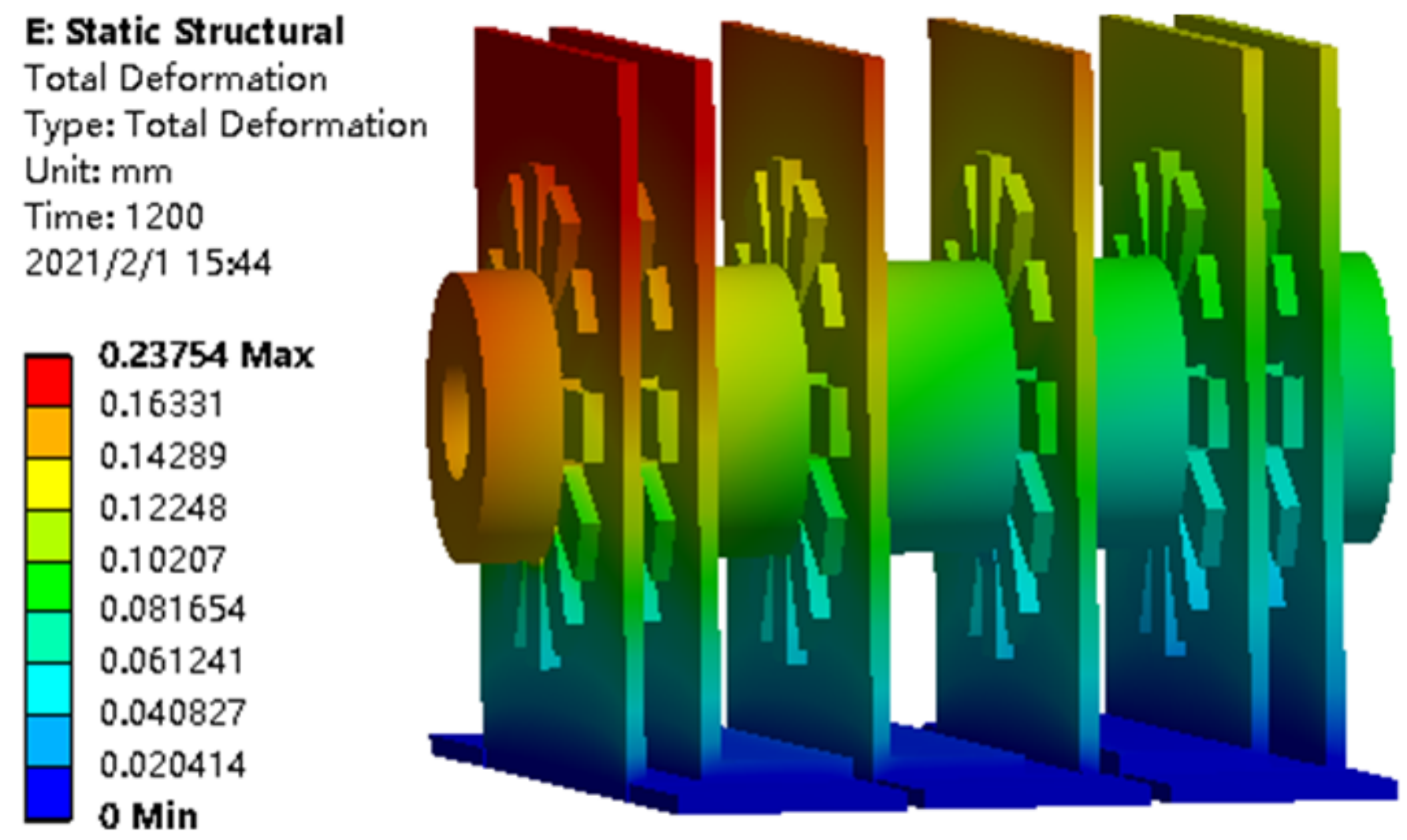

Figure 10

The thermal deformation of conductive shaft

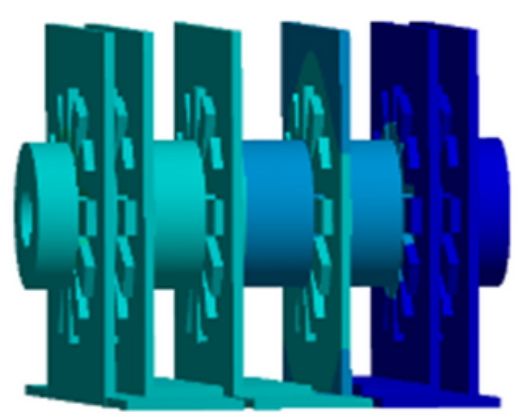

(a) $12000 \mathrm{~A}$

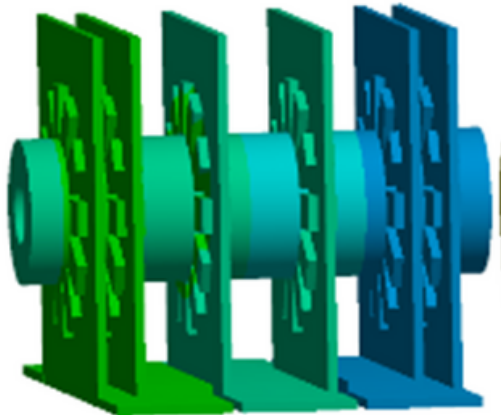

(b) $15000 \mathrm{~A}$

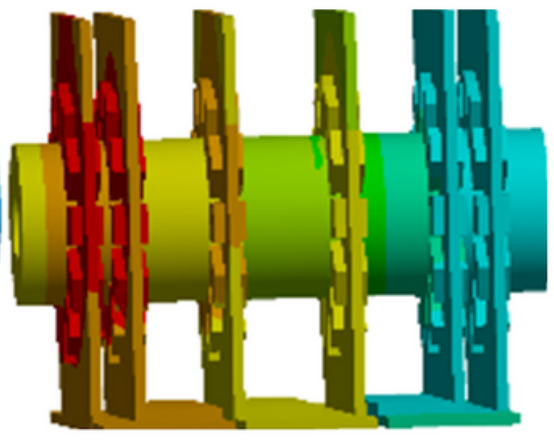

(c) $20000 \mathrm{~A}$

Temperature

Type:Temperature

Unit: ${ }^{\circ} \mathrm{C}$

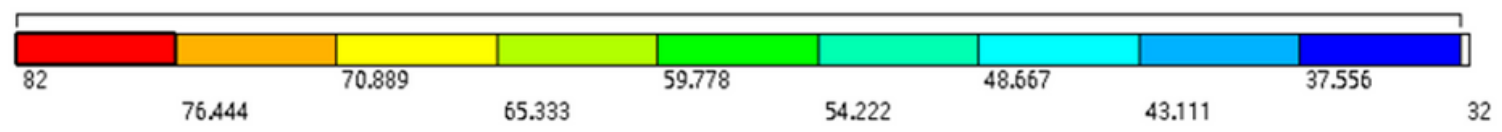

Figure 11

The temperature field distribution of conductive shaft under different processing currents 


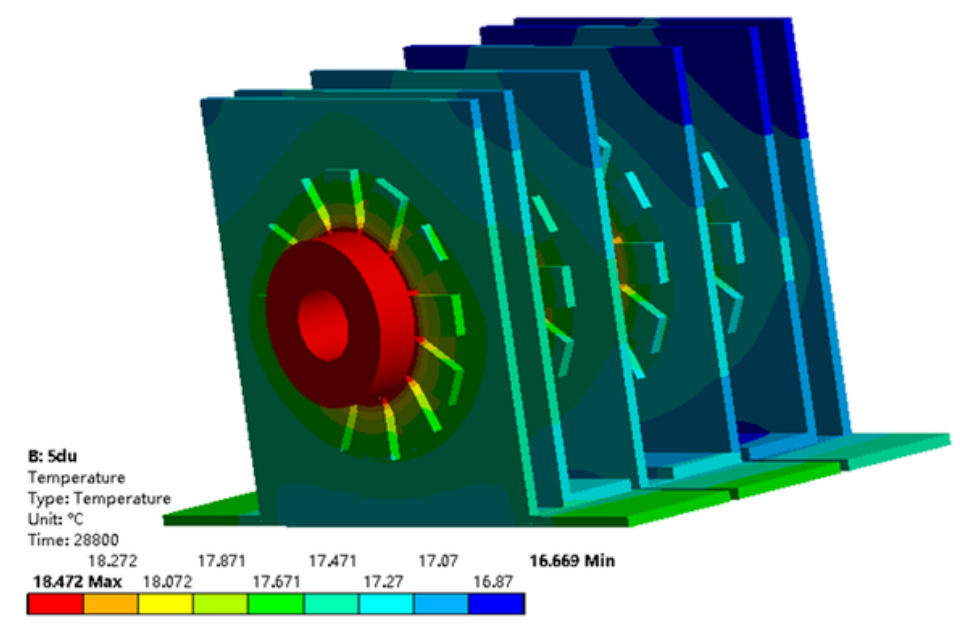

(a) $5^{\circ} \mathrm{C}$

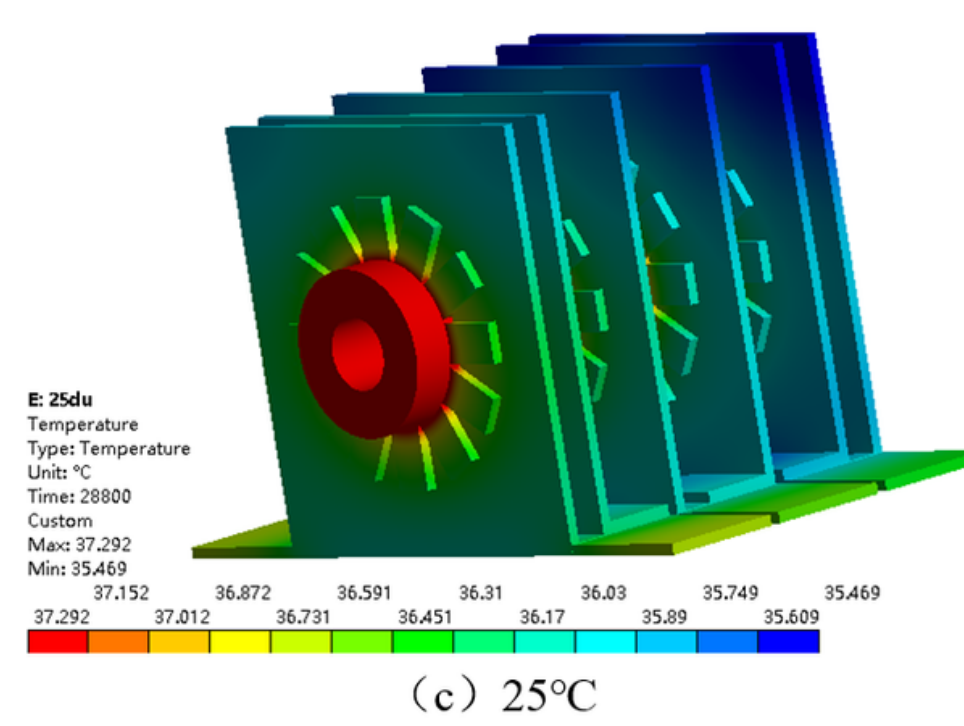

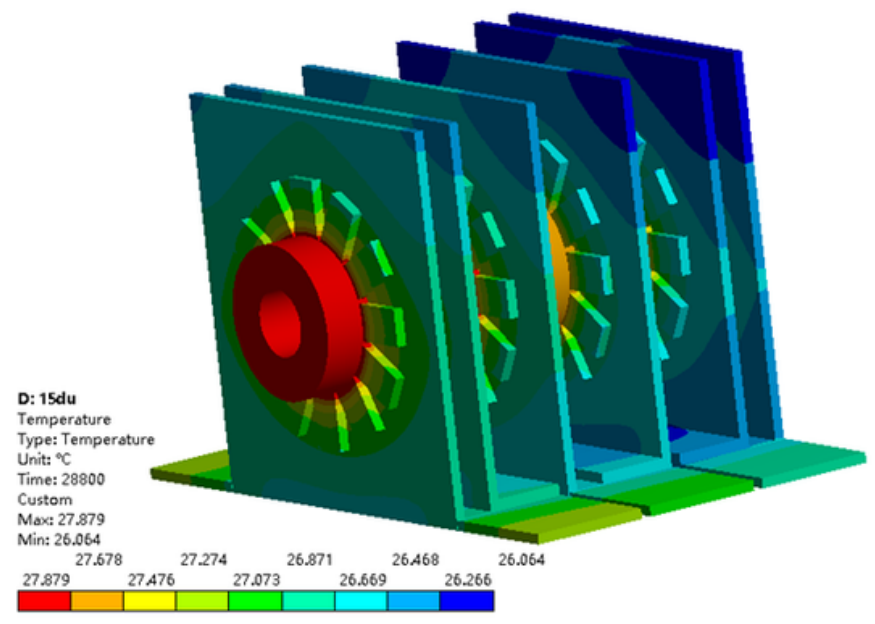

(b) $15^{\circ} \mathrm{C}$

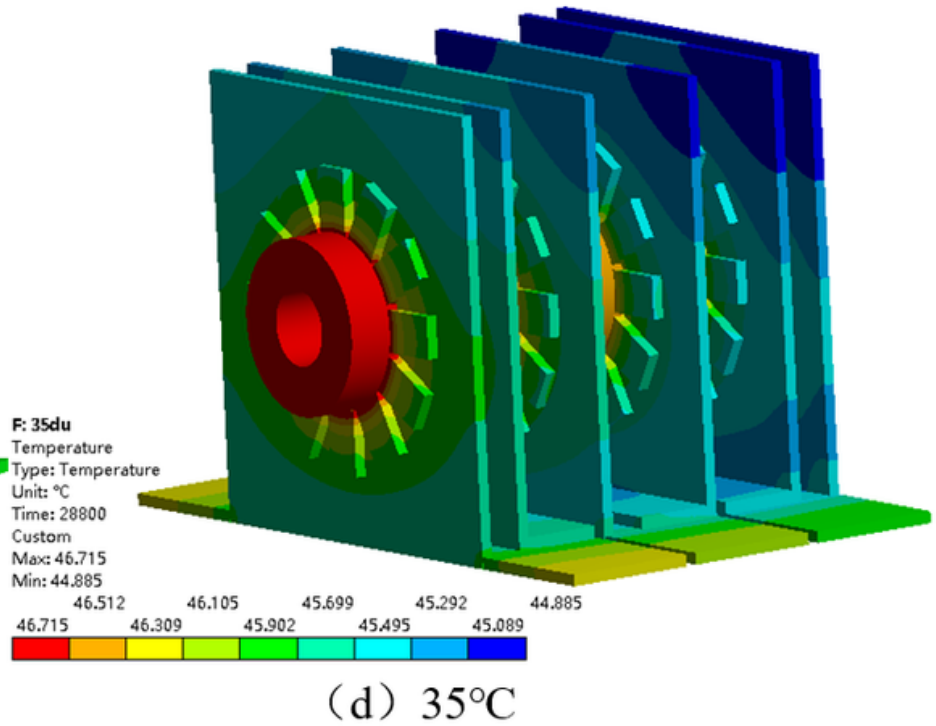

Figure 12

The distribution law of temperature field 


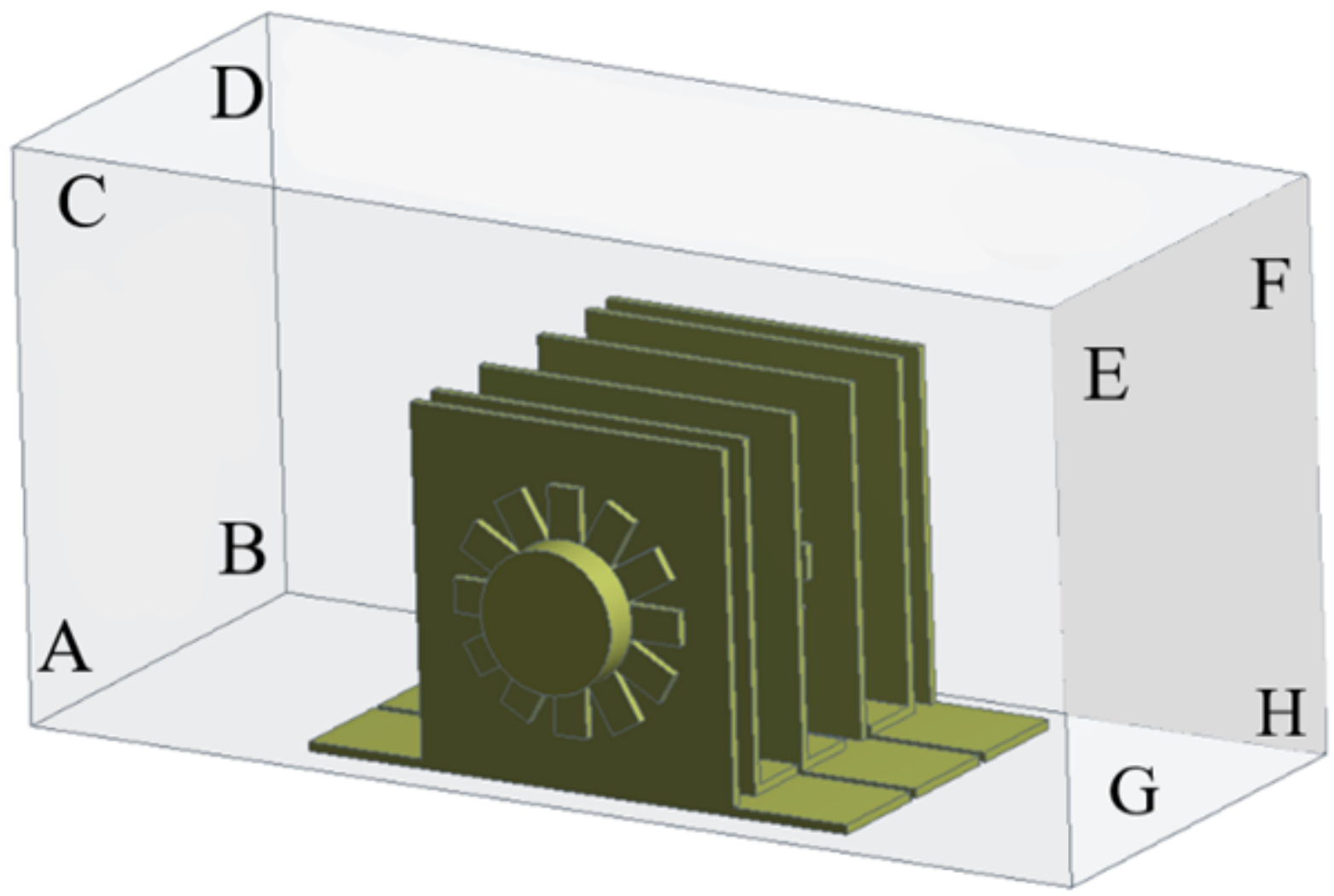

Figure 13

The conductive shaft and box model

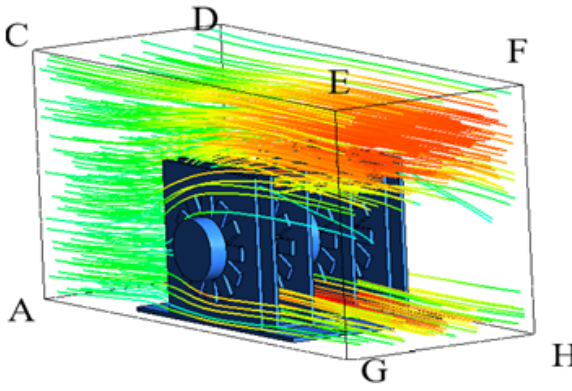

(a) Scheme I

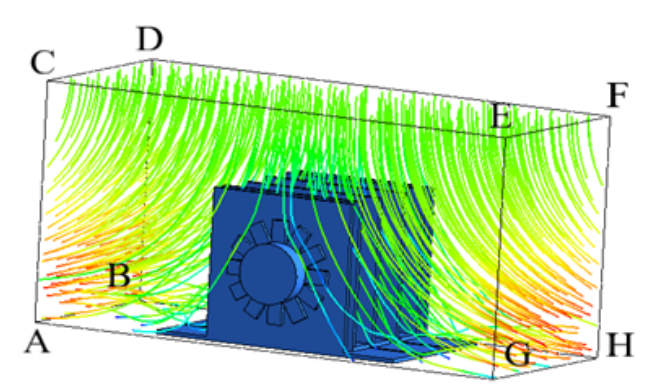

(b) Scheme II

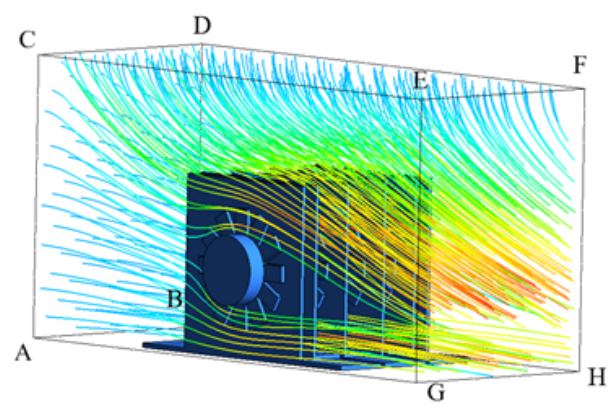

(c) Scheme III

Temperature

Type:Temperature

Unit: ${ }^{\circ} \mathrm{C}$

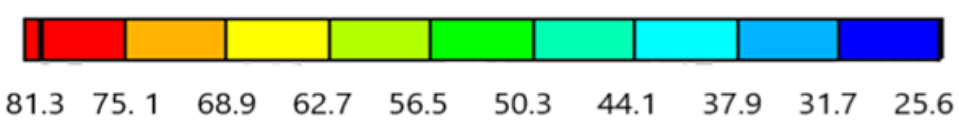

\section{Figure 14}

The flow field distribution of different air sources 


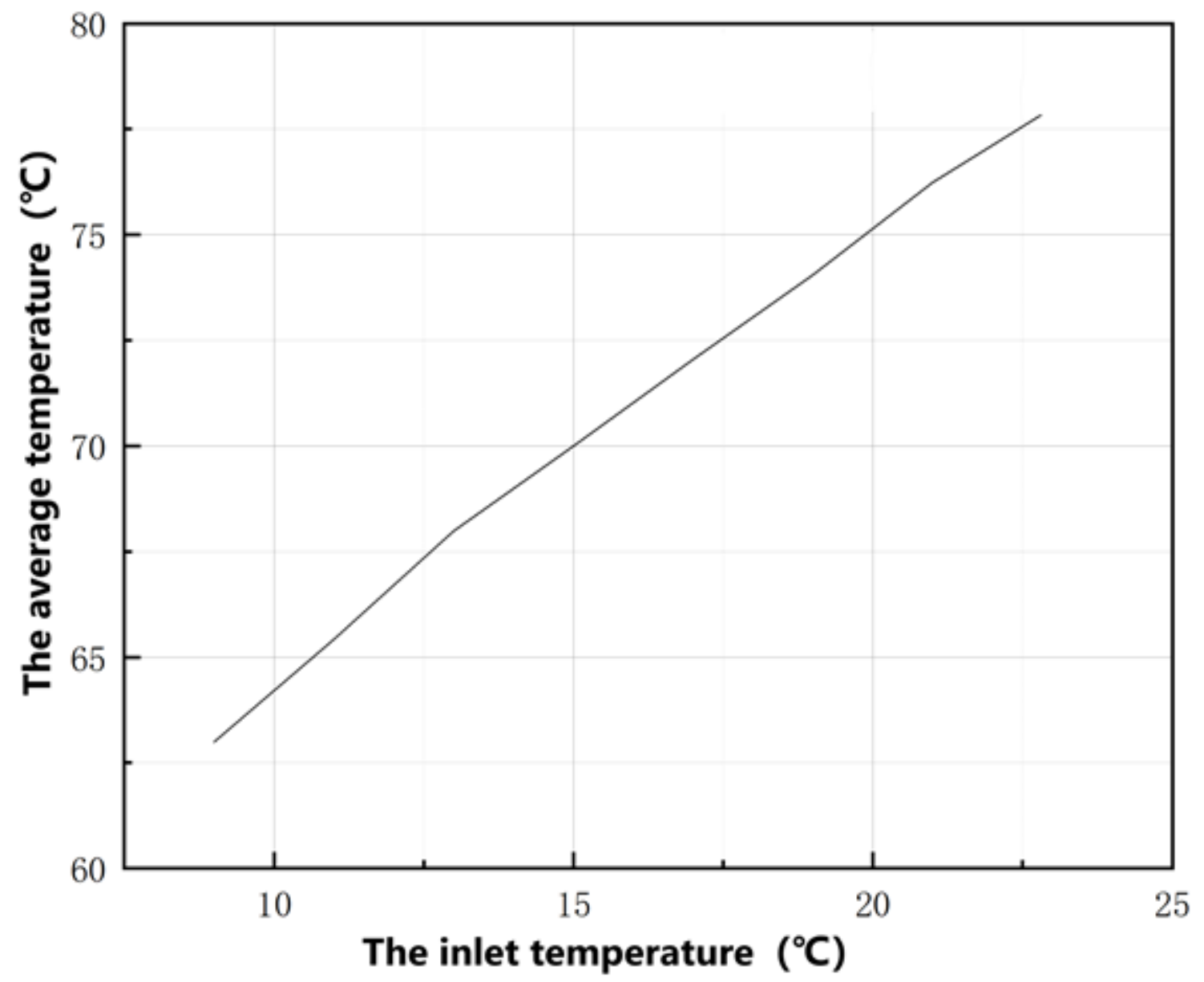

Figure 15

The variation of average temperature in axle box with inlet temperature

2

Figure 16

The physical drawing of conductive axle box 


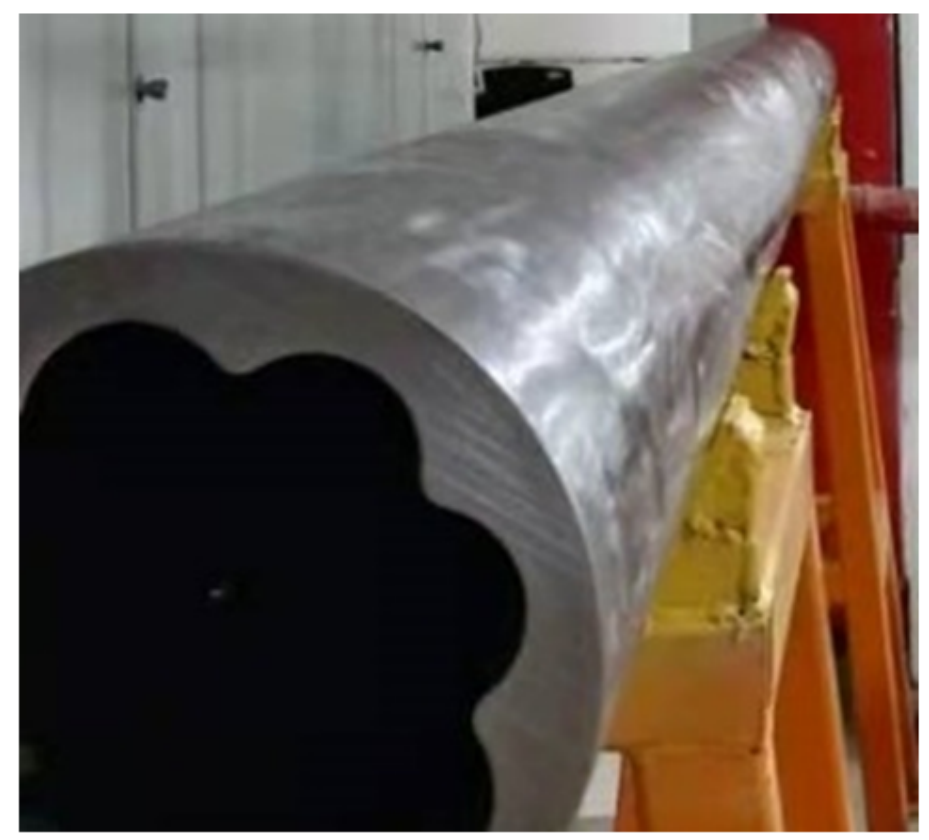

(a) The complete workpiece

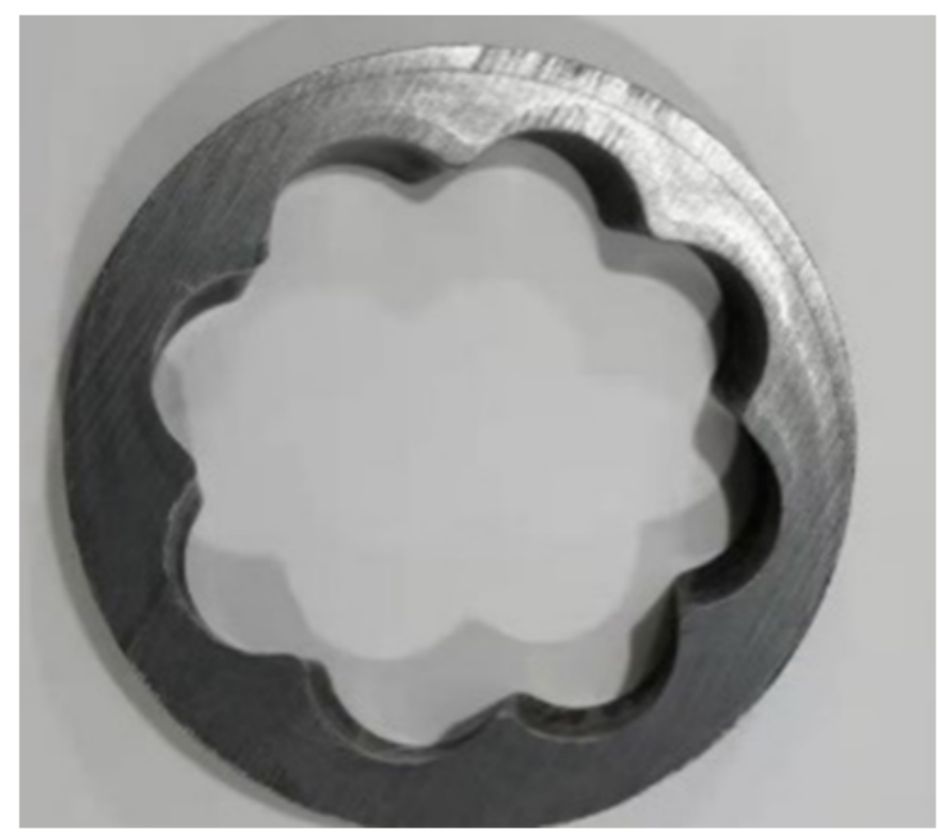

(b) The workpiece slice

Figure 17

The processed workpiece 